\title{
ABOUT COMMUNICATION IN SOCIAL MEDIA - AN ANALYSIS OF THE POLISH PRESIDENCY FACEBOOK PROFILE FROM A PERSPECTIVE OF SOCIAL COMMUNICATION THEORY
}

\author{
MARTYNA TOMICZEK \\ martyna.tomiczek@uni.wroc.pl \\ University of Wrocław, Poland
}

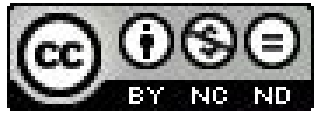

\begin{abstract}
The half year of the Polish Presidency on the one hand was a great challenge but from the other hand a tremendous chance to promote the country and society. Activities were taken up in many different areas - using new technologies was an important part of the project, including new media which by the creation of the Polish Presidency Facebook Profile turned out to be an integral part of Presidency. Using the possibility of providing a two-way communication proved that the potential of Facebook was understood. Running the fan page also showed a new face of diplomacy putting it in the area of public diplomacy.
\end{abstract}

Key words: Polish Presidency, Facebook, Facebook Profile, communication, public diplomacy, new dimension of education.

\section{INTRODUCTION}

"Introducing the European Union onto a path of a rapid economic growth and empowering its political strength are principal objectives of a Polish Presidency. In order to achieve these objectives, the Polish Presidency wants to focus on three priorities: European Integration as a source of growth, a safe Europe and a Europe taking advantage of openness". (http://pl2011.eu/program_and_priorities)

These words are to be found on the Polish Presidency official website. They prove that 6 months of leading the European Union was a very significant period for Poland and for Poles. The people responsible for this project faced a challenge of professional conduct in all activities including informing society about progress in reaching previously assumed results by means of modern communication technologies - social media. The usage of social media in the Polish Presidency campaign could be regarded as a mark of a new form of education - in this case we could talk about a new dimension of image campaign education. Traditional methods of education are based on the direct process of education or usage of media communication, which exclude the possibility of interaction and dialogue. Social media mechanisms allow engagement with Internet users in a more complicated but more effective process of education.

In this paper I will attempt to analyse the Polish Presidency Facebook Profile from the perspective of social communication theory. More precisely - this paper's objective would be to answer the following questions which are the basis for conducting the analysis (questions listed below would mark the paper's structure only in part, because answers to certain of them would be sought at different moments): 
1. Who could be the gatekeeper? In which way should the process of selecting information on the Facebook Profile be conducted? Could the gatekeeper's input be easily detected?

2. What character has information on the Facebook Profile - redundant or entropic in terms of the Shannon and Weaver communication model?

3. Could examples of communication noise be found on the Facebook Profile? How could they be identified?

4. To whom are messages devoted? Could a specific group of receivers be identified?

5. How is a non-verbal communication conducted on the Facebook Profile? How could its functions be defined?

6. Which type of communication could be observed on the Facebook Profile?

\section{COMMUNICATION ON THE POLISH PRESIDENCY FACEBOOK PROFILE AS AN EXAMPLE OF MASS COMMUNICATION}

Contemporary communication theory designates three ways in which people are able to communicate with each other: direct communication - interpersonal, indirect communication - mass communication and media communication (this type of communication has been identified as a last one because of the dynamic development of mass media and new communication technologies, which has changed dramatically all dimensions of people's lives).

Wlodzimierz Głodkowski describes interpersonal communication as a "process of sending and receiving information between two persons or small group of people, which creates specified results and types of feedback" (Głodowski 1994, p. 5). Among the most important features of the direct interpersonal communication is the possibility of obtaining immediate feedback, the bilateral character of the communication process and its interactivity (at least two subjects are indispensable) should be enumerated (Dobek-Ostrowska 2004b, p. 20-21).

Media interpersonal communication is a type of communication in which the information sender and information receiver do not participate in a direct psychical contact, but at the same time a certain specific type of the feedback takes place in the form of both non-verbal and verbal communication. Using telephones to communicate, participating in on-line conferencing, talking via Skype could all be regared as examples of the media interpersonal communication - in other words, media interpersonal communication appears when modern technologies are used in the process of communication (B. Dobek-Ostrowska 2004b, p. 22).

Taking into account the Polish Presidency Faceobook Profile analysis, undoubtedly the mass communication could be seen as a dominant type of communication (Dobek-Ostrowska, 2004b, p. 22-24).

An impersonal character could be defined as a substantial feature of this type of communication - participants of the whole process or just of one communication unit do not have the opportunity to experience direct contact. Nevertheless, the possibility of compiling a personal profile or a fan page with photographs mitigates in a certain specific way the inconvenience generated by the lack of possibility to meet 
your conversation partner. Obviously, this kind of activity cannot be a substitute for direct face to face interaction. However, on the other hand an analysis of traditional forms of the indirect communication (an e-mail communication for example) could easily prove that nowadays, in the era of so-called new media, we are witnessing a qualitative change - adding photographs, which displayed together with posts and comments could be regarded as a substitute for face to face interaction. The conversationalist is no longer seen as an anonymous, unknown, strange and unreal subject - seeing somebody, we may feel that we participate in real conversation.

Inserting those photographs could be considered in different categories: as a mean of self - promotion, as an attempt to find new acquaintanceships but also as a new stage of being present in a virtual reality, which has been evolving recently from being a place, in which many anonymous subjects employing pseudonyms and replacing their faces with avatars, to a space where embodied subjects have the opportunity to exchange opinions and get to know each other in more detailed way - in my opinion, the following contention could be drawn: showing the face (in photographs) could be interpreted as a symbolic act confirming willingness to obtrude and preparedness for revealing one's opinions, thoughts and engaging in polemics and dialogue (not always a constructive one). Undoubtedly, a certain percentage of Facebook users still employ their avatars and pseudonyms instead of real names and images, but this does not change the fact that a great circle of registered users have revealed themselves - however, it is worth deliberating here whether the cause of this phenomenon (the symbolic act of revealing yourself in front of the world) lies more in the pursuit of changing Facebook profiles in a space of conducting constructive dialogues and discussions or rather be analysed as a result of the enormous popularity of Facebook?

Another distinctive feature of the mass communication is belated feedback, which Bogusława Dobek - Ostrowska characterises as "a receiver's reaction after decoding information. It tells us if the piece of information has been heard, seen and understood" (Dobek-Ostrowska 2004b, p. 17). Symptoms of such a kind of feedback could be observed on the Polish Presidency Facebook Profile - they were materialised in official answers given by the Polish Presidency Team administrating the Facebook fan page to individuals who were asking different questions or striving to share with their opinions by inserting more or less elaborate comments. It is obvious that it was impossible to answer all questions or all comments raised - it would have deranged the Polish Presidency Profile functions owing to non essential delving into disputations with only a narrow group of active individuals and moreover required an engagement of more human resources being responsible for communication with people visiting the Polish Presidency Facebook Profile. Therefore, the Polish Presidency Team responded only to chosen posts inserted on the fan page (an average time of receiving an answer was 49 minutes).

In the perspective of conducted analysis, the feedback should have been considered as a significant element of a two-way communication process. It is worth emphasising once again, that the essence of Facebook communication is hidden in the possibility of conducting the two-way communication through employing the possibility of inserting own posts and commenting on others' opinions. On the one hand, the mentioned function could have been analysed in terms of being a chance for buil- 
ding relations with the Polish Presidency Profile users but on the other point of view, it was a great challenge taking into account the massive character of the receiver. The process of building such kinds of relations on the Polish Presidency Profile redounded considerably to transformation of traditional diplomacy, which had been reserved to a limited group of diplomats and other government officials from the beginning of creating this discipline. The traditional diplomacy could be described as "behind closed doors" - an average citizen had not been allowed to participate - it could be claimed that he has been a passive receiver of meticulously selected diplomatic information, which has been sent by the traditional mass media to a society unable to influence the content of these messages or to shape reality in any significant way. The state of affairs mentioned above has been radically evolving since new technologies, including new media, appeared in peoples' lives. The majority of them create an unique opportunity for the mass receiver to participate in two-way oriented communication interactions.

The Polish Presidency Team made the effort and began to participate in the process of two-way communication with individuals filling up the fan page with their private comments inserted as rejoinders to official statements and information. As an example we may consider an exchange of active users' opinions being a response to the post from $11^{\text {th }}$ January 2012 concerning the case of handing over the European Union Leadership from Poland to Denmark. This event evoked an eager dispute pertaining to total expenditure borne by Polish society within the 6 months period of the Polish Presidency. The discussion revealed many dissenting voices - undermentioned quotations represent those opinions:

1. "100 000000 euro (450 000000 Polish zlotys) for promotion of culture and tourism of a few Polish regions? Cosmic money! Compare with cultish "I love New York « campaign which lasted more than year and caused visits of more than 48 million tourists and cost less than 30 million USD" (http:// www.facebook.com/\#!/PolskaPrezydencja2011?sk=wall)

2. "As I wrote to you - no average Kowalski [synonym of an average Polish citizen - M.T.] has had anything from this presidency and what is more he has had to pay for it. Poland has nothing from this presidency and it would change nothing if it had not taken place. What are the plus points of this presidency?" (http://www.facebook.com/\#!/PolskaPrezydencja2011?sk=wall)

What is important and worth emphasizing, is that the Polish Presidency Facebook Profile Team did not ignore these objections and strove to explain to appalled Internet users the different niceties connected with realisation of such complicated project as the 6 month long Polish Presidency. To picture this observation, the undermentioned example should be analysed in more detail.

Between $10^{\text {th }}$ and $11^{\text {th }}$ January 2012 the Polish Presidency fan page was a platform of discussion over the Presidency budget. As I already indicated above, the majority of people actively commenting, expressed dubiousness. The Polish Presidency Team honoured those concerns and engaged by sending responses, which could be read as a proof of conducting a two-way communication process - its main objective is to listen and analyse interlocutors' arguments and conducting dialogue or substantive, fact-based discussion. An example of such constructive polemics is descri- 
bed below: "How is it - richer Denmark will spend 30\% less for presidency than Poland. I require an answer" (http://www.facebook.com/\#!/PolskaPrezydencja2011?sk=wall). Disputant received a following respond: "(...) as we wrote above the difference concerns i.a. the number of meetings (Danes will organise only $50 \%$ of the total number of meetings we organised), but we have to also remember that we had an entirely different model from the Danish presidency. That means - we endeavoured to take advantage of the presidency's promotional potentiality and decided to organise meetings in 5 different regions - the Danes will prepare meetings only in 2 cities. Budgets should be compared with former presidencies - the cases of many countries showed that expenditures estimated in the beginning turned out to be far too low when related to the final costs. Another thing is that it is difficult for us to comment the Danish presidency budget, because we do not know in details what it contains - that means: does it contain only central expenditures or also costs of other units? Our budget includes the total amount of all costs" (http://www.facebook. com/\#!/PolskaPrezydencja2011?sk=wall).

A complete declamation comprising substantive arguments aiming at informing users about facts (i.a. there was precise information about the exact number of places where promotional activities would take place) rather than imposing a change of a private opinion - in the context of the response analysed above and other responses of the Polish Presidency Team (which can not be adduced here in larger number for obvious reasons), it could be claimed that the Team was perceptibly and consistently employing the communication model based on conducting dialogue (it could be observed throughout the analysis of posts creating all together a lively discussion between Polish Presidency opponents and proponents and the Team, that people responsible for the official Presidency Facebook Profile knew notions such as active listening, dialogue, fact, assessment and understood the importance of employing this knowledge properly and with respect to users visiting the Presidency Facebook Profile). Moreover, such type of professional communication was also employed by the Team in difficult and often controversial situations - this should be particularly emphasized as it proved maturity of the Team.

The conclusion could be framed as follows: although the communication on the Polish Presidency Facebook Profile should have been classified as mass communication, it had been transformed into a specific form that should be regarded in terms of a conjunction between media interpersonal and direct interpersonal communication - the media direct interpersonal communication appeared as a new type of communication.

\section{COMMUNICATION NOISES ON THE PRESIDENCY FACEBOOK PROFILE}

Communication noises are "all sounds incidental to sending and receiving the signal" (Dobek-Ostrowska 2004b, p. 17) - each of them "is capable of impeding the communication process at the decoding stage" (Dobek-Ostrowska 2004b, p. 17). In other words, these are all types of disturbances that considerably trammel or even disenable an accurate, that is coincident with the sender's intention, 
understanding of information. B. Dobek - Ostrowska identifies three types of the communication noise:

- external - refers to exogenous factors of the communication process, such as temperature, turmoil, device defect etc.,

- internal - includes all kinds of emotions, receiver's psychological condition and his attitude toward the content of information

- semantic - is connected with the form of information - if the sender advisedly or unconsciously builds improper information in the semantic sense, the probability of its misreading will grow considerably (Dobek-Ostrowska 2004b, p. 17).

The nature of the communication process proves that absolute elimination of noise is almost impossible - although it should be pointed out that the external type of noise could be controlled most easily.

Considering the specific of the Polish Presidency Facebook Profile, the semantic noise should have been regarded as the subject of analysis - an analysis of internal noises would have required researching the group visiting the fan page and those who clicked the "Like" button.

The analysis revealed that an enormous accumulation of different information should have been regarded as the main source of semantic noise. In one space, on the so-called board, we could have found the following news: a post concerning the termination of Jerzy Buzek tenure and approaching election for the new Chair of the European Parliament, a post referring to the visual project of the Danish Presidency, below there was a link to the article of Pawel Potoroczyn, the Executive of the Adam Mickiewicz Institute, in which he was summarising cultural achievements of the Polish Presidency and emphasizing its uniqueness. Subsequent news was a puzzle - next in a pre-planned cycle aiming at entertaining visitors and engaging them in activity. The so-called board could have been perceived as a space which, first of all, should have been used for informing visitors about latest news; secondly, as a space, which should have attracted attention by its freshness (understood as inserting the latest news systematically), intriguing and motivational to regular visitations, circulating inserted posts to friends and interacting with people being interested in activities taking place pending the period of the Polish Presidency; thirdly, as a space for promoting a positive picture of Poland and Poles (however, it has to be mentioned and stressed that promotional activities seemed to have been limited to receivers being able to understand the Polish language since the Polish Presidency Profile had not been translated into English - excluding the welcoming information which could have been translated by clicking on proper icon. This situation contributed to confirming the influence of the process of constructing a picture of modern, open - minded Poland and creating a forum for foreign users interested in the Polish Presidency period. Although, such accumulation of different posts on the Polish Presidency Profile's board appeared to be clear and completely understood in the context of its role, nevertheless it gave a perception of a certain chaos - especially for people who were not fluent in dealing with Facebook applications and the structure of profiles which, what is more, usually remain constant only for a period 
of time. Nonetheless, almost every post was constructed in a very clear way: having the same structure as others, making it easier to decode.

The multifaceted content of information inserted on the Polish Presidency Profile's board should have been definitely regarded as the next source of semantic noise. Undoubtedly, certain news reguired from visitors a wide knowledge i.a. about Polish foreign policy, different aspects connected with the European Union and the activity of its politicians, diplomats and individuals engaged in the Polish Presidency Programme - in other words, in order to understand certain posts properly, a wide and even specialised knowledge was indispensable. To illustrate this, the following news item from $25^{\text {th }}$ November 2011 could be quoted: "An informal meeting of Ministers of the Coherence Policy of the European Union starts in Poznan. It is a very important area, because within its framework we are attempting to equalize differences in regional development in the UE. What examples of investments realised in your area thanks to the structural fund do you know?" (http:/ / www.facebook.com/\#!/PolskaPrezydencja2011?sk=wall).

At the first sight, such an intensive spate of often very differing news and the additional factor such as complicated content of certain published information could have been perceived in terms of communication noise identified in the Shannon-Weaver model (See: J. Fiske 1999, p. 21-40) as trammeling an accurate understanding. Nonetheless, it ought to be remembered that profiles boards on Facebook are destined for conducting such kinds of communication. Therefore it is not an improper usage of Internet space that should be considered as a noise source but rather a lack of competencies necessary for being capable to navigate within it.

\section{THE ACTIVITY OF MODERATORS ON THE POLISH PRESIDENCY FACEBOOK PROFILE}

The moderator's most imporant and essential role ${ }^{25}$ is to eliminate communication noise and select and reduce primarily redundant news - that is uncomplicated information, which relates little to the process of decoding. If we assume, that the communication on the Polish Presidency Profile was a manifestation of a political communication (See: B. Dobek-Ostrowska 2004a, p. 19-22) being directed to gain citizens' endorsement for the half-year long project coordinated by the government, funded i.a. from public money and to create a professional, positive image of the people managing all activites connected with this special period, the mediator's role could have been considered in the terms of the agenda-setting theory enunciated by Rogers and Dearing (Dobek-Ostrowska 2004a, p. 119), in which three types of agenda were desribed: the media agenda, the public agenda (public opinion) and the political agenda. Although each of them has it own objectives and interests, they are dependent from each other and therefore in order to succeed, they are obliged to cooperate. In the case of the Polish Presidency this cooperation could have been achieved in two ways:

$25 \quad$ A moderator is a person or a group of people responsible for selection of information appearing in the media (B. Dobek-Ostrowska 2004a, s. 32) 
- by active listening to the media and political agenda representatives as to the needs expressed by Internet users,

- by eliminating negative and prejudiced comments in order to achive the realisation of the image-building objectives

The analysis however proved that despite of moderators' presence (it could be assumed that the their role was in hands of the Polish Presidency Team - it was a natural and logical solution as those people were most engaged in the Polish Presidency Profile's "life"), negative posts were not removed. As an example, the following dialogue could be quoted: an Internet user wrote in incisive words that "the conception of the Polish Presidency is tragicomic - without order and structure, without any depeer thought! I am ashamed that it looks so tragic!!! Shame and disgrace:(" (http://www.facebook.com/\#!/PolskaPrezydencja2011?sk=wall) - he received the following answer from the Team: „,(..)why? Activites are in accordance with the previously accepted programme and many of the core objectives have already been already achieved" (http://www.facebook.com/\#!/ PolskaPrezydencja2011?sk=wall).

In my opinion, it is worth mentioning once again that the inimical comment was not removed and what is more, was accompanied by a response encouraging further discussion. A similar regularity could have been observed in another situation of this kind, what could be regarded as a confirmation that the moderator's role was to react on current news and explain all doubts.

\section{REDUNDANCY AND ENTROPIC INFORMATION ON THE PROFILE}

The notion "redundancy" and its opposition "entropy" are two main concepts of the Shannon and Weaver communication model (See: Fiske 1999, p. 21-40) they state that "redundancy is that which is predictable or conventional in the message. The opposition of the redundancy is the entropy. Redundacy is a result of large verisimilitude and the entropy of a small one - that is a message with small probability is entropic and contains much information. Conversely, a message with large verisimilitude is redundant and contains a small amount of information" (Fiske 1999, p. 26). The redundancy and from the other side the entropy of posts, news and reponses inserted on the Polish Presidency Facebook Profile had an enormous influence on the decoding process, particularly in circumstances where the mass receiver is characterised by great diffuseness of demographic features (such as age, social status, place of living etc.), attitudes and opinions had to be taken into account. In general, the main difficulty in building messages for the mass receiver (mass audience) relies most of all on the fact that they should be understandable for the majority - therefore messages directed to a mass audience, should not contain a specialised knowledge resulting in discouraging a section of visitors from tracking messages systematically and should not employ complicated terminology required in advanced competencies in order to be decomposed and, in the final effect, understood. It seems then, that the Polish Presidency Team should have concentrated on preparing redundant information, which would eliminate problems connected with proper decoding. 
The Polish Presidency Profile analysis revealed that there were hardly any suprising, shocking news on the fan page, which would have disrupted the general communication system of the Polish Presidency Team. Firstly, the message content was predictable - it referred to different situations and events connected with the Polish Presidency Programme (they could have been perceived as an abridged relation or linkage to more elaborated articles, presentation and performances), informed about progress, the Polish Presidency's perception abroad and summarised 6 month-long period (visitors could have read about expenditures and different statistics). Secondly, the redundancy was also hidden in the style in which messages were written - instead of extreme emotions, aggression and personal attacks, Internet users visiting the Polish Presidency Profile could have experienced a professional attitude of the Team. One very interesting phenomenon has, however, to be pointed out - the majority of messages (posts, news, comments) had rather unofficial form evincing in employing casual expressions and substitutes of emotions - such popular emoticons. This communication style was consequently used in nearly all Polish Presidency Profile spaces and in nearly all messages - both if the conversations with visitors were considered (in one of such dialogues referring to a competition for preparing proposals for the Polish Presidency poster, an Internet user wrote that "I sent you 2 hours ago my second poster on you mail, because I could not use the 'Publish' button...Did you receive my message?:(All the best..." and he received a following response: „(...) published. Thanks for patience:-)" (http://www. facebook.com/\#!/PolskaPrezydencja2011?sk=wall).

And if inserting new messages was regarded - however in this case an additional regularity could have been observed. Namely, from messages informing about the most official events the diminutives and emoticons were excised - arguably in order to add weight to its meaning. This mentioned frequency could have been pictured by different form of following information:

a) "Only few days left till the end of the auction with the Polish Presidency presents witihin the action of supporting Wielkiej Orkiestry Swiatecznej Pomocy [it is a regularly organised charity event - MT]. And below there is a short movie with Jurek Owsiak also encouraging for bidding" (http://www. facebook.com/\#!/PolskaPrezydencja2011?sk=wall:).

b) „Today Donald Tusk will participate in offical inauguration of the Danish Presidency in Copenhagen. A meeting with Prime Minister Helle Thorning-Shmidt concerning cooperation within three presidencies will also take place" (http://www.facebook.com/\#!/PolskaPrezydencja2011?sk=wall).

The difference in the style of communication revealed in the quoted examples explicitly proved that there were two methods of conducting communication implemented on the Polish Presidency Facebook Profile - a deduction could be that the messages had contextual character (on the one hand, the communication method was dovetailed with the content and from the other hand with receiver). It confirmed that the Polish Presidency Team was a group of professionals who were aware and had knowledge essential to form information adequate to the type of particular event or situation - therefore the communication on the Polish 
Presidency Profile could have been definied as elasticated and motivated by willingness to conform the message content to the particular context. When the objective was to inform about an imporant and officially planned event, the post was written in a serious style. However, in the process of interacting with Internet users visiting the Polish Presidency Profile, the Team consequently deployed more casual style of communication (framed in dialogues, comments, news etc.) due to what the communication - understood in a holistic way - seemed to have been perceived as more plausible for an average receiver who tended to use emoticons, brachylogies and diminutives in day-to-day conversations.

Due to implementing the redundant communication, the Polish Presidency Facebook Profile could have been described as more open and more available to a larger group of potential receivers. Building clear, uncomplicated messages and deploying chosen elements of casual communication (when it seemed desirable) were completely understood and, what is more, essential, because it was almost impossible to create different groups characterised by similar demographical features which could have been treated as a base for formulating news dedicated to those groups and not for all visitors

\section{NON-VERBAL COMMUNICATION}

David Matsumoto and Linda Juang, the authors of Culture and psychology, claim that non-verbal communication comprises two pivotal parts (Matsumoto, Juang, 2007, p. 344-345):

- non-verbal behaviour - these are: facial expression, gestures (including hand, shoulder and leg gestures), body position, voice (its timbre, intonation, speaking pace - in general the speaking manner), interpersonal space, haptic and optic behaviour

- non-behavioural elements - these are all signals communicating certain specified meanings, but not referring to determined behaviour (such information carriers as time management, dress code, physical ambience could be interpreted as non-bahevioural elements)

It would be valuable to systematise the knowledge concerning the role of non-verbal communication in the process of communication understood holistically. The crucial point is to realise that the non-verbal and verbal communication are closely associated and it would be a mistake to separate them. The same opinion has Adam Kendon as he writes that " $(. .$.$) gesticulation is organised around the$ same units which organise the speech proces...gestures and the speech constitute two distinct methods of representation, but their action is coordinated as both systems serve the same superordinate purpose. This purpose is to create an action pattern being able to reflect the intentional meaning" (Kendon 1983, in: M. L. Knapp, J. A. Hall 1997, p. 32). Remembering this presupposition, the following functions of non-verbal communication in the process of communication could be enumerated: expressing emotions, informing about interpersonal relations, presenting personality, attracting conversation partner attention) or, taking 
into account a different categorisation, the role of non-verbal communication could be regarded as: repeating, ambivalence (experimental results have revealed that if there is a contradiction between verbal and non-verbal communication, receivers will interpret non-verbal signals as more plausible), completing, replacing, regulating and accenting/moderating.

The non-verbal communication on the Polish Presidency Facebook Profile could have been observed especially in the photograph gallery containing 411 elements on the 13th of January 2012. Pictures were sorted in different thematic-oriented categories - everyone entering in the gallery space could have chosen between photorelations from official events (i.a. European Development Days 2011, signing of Croatia Accession Treaty, Presidency Meeting in Poznań or in Cracow etc.) or from unofficial occasions (such as a spontaneous Flash-mob organised in Warsaw).

Considering the sort of graphic materials inserted in galleries, pictures, infographics and other types of visual material were employed, which indubitably contributed to creating an interesting Internet space for visitors who did not feel overwhelmed by only one type of graphic material. Furthermore, the gallery served as a means to interact with Internet users - it is worth analysing the example of a gallery with projects sent to the competition for the best Polish Presidency poster: inserting all propositions into a separate, specially prepared space proved that the Team treated visitors with respect and appreciated their efforts. Certainly, this attitude caused competitors and other Internet users to feel appreciated, not ignored, which contributed in the end to the augmentation of the probability of clicking "Like it” on the Polish Presidency fan page and expressing positive opinions in the active discussions. At the same time, it proved that the Team was aware how important and crucial were activities engaging visitors being potential symphatisers with the Polish Presidency, developing an interaction with them and pertaining to their activity (for example by responding to their questions or publishing photographs presenting spontaneous citizens' participation in events organised by the Polish Presidency Group). It is obvious then that people attending the Polish Presidency Facebook Profile took a great care over emphasising Poles' contribution to different events included in the Polish Presidency Programme. This measure was favourable to building the Polish Presidency image perceived as a sequence of activities controlled by government officials esteeming the cooperation with Polish society.

Summarising, it is worth accenting that the non-verbal communication on the Polish Presidency Facebook Profile had two functions: on the one hand, it was an informing function (Internet users were able to find posts devoted to events and pictures being a visual relation from different activities - both adequate and corresponding with news' content, which contributed to reinforcing the messages) and on the other hand, it was a building-relation function aiming i.a. to motivate Poles to a wider participation and engagement in the Polish Presidency Programme whose objective was to construct a positive image of Poland and Poles abroad. 


\section{INFORMATION AND PERSUASION IN COMMUNICATION ON THE POLISH PRESIDENCY PROFILE}

The theory of communication identifies two types of communication:

- informing communication - its pivotal objective is "creating bilateral agreement and understanding among participants of the process, sharing the knowledge, explaining and briefing (...)" (Dobek-Ostrowska 2004b, p. 30).

- persuasive communication - through employing this type of communication, the sender "(...) strives to influence the other person in order to change his reaction, behaviour, form new attitudes or modify already existing and prompt to action"(Dobek-Ostrowska 2004b, p. 33).

Both types could have been observed on the Polish Presidency Profile - however, it is obvious that the persuasive communication was conducted indirectly. Since the informing communication has already been analysed before, the persuasive communication would be described in this part of the paper.

In my opinion, elements of persuasion could have been distinguished in employing a specific language and in the form of conducting discussions. Controlling emotions and conducting constructive discussions could have been regarded as natural and obvious measures - the Facebook Team was representing the Polish government and could have been described as one of the Presidency's "faces" and therefore did not afford personal attacks or emotional assessing of visitors' comments. What is interesting, is that when a particular post had more casual character, the Team accommodated its response to the unofficial style - it could be stated then that the Team's reaction was situation - based and very flexible. On the other hand however, this flexibility could have been regarded as an element of self-image manipulation - this method of manipulation is precisely described by Tomasz Witkowski: "methods of talking about yourself positively and showing yourself from the best side are often sophisticated measures based on talking about people we know, presenting our knowledge, doing many things including skilful exposition of modesty in order to present yourself in the best way" (Witkowski 2004, p. 57). The modesty was revealed especially in situations when moderators put their efforts to explain to Internets users those aspects of activities which were unclear for them and required an amplification. What was symptomatic for the communication style implemented on the Polish Presidency Profile, was that on the Team's side there was no presumptuousness, gloating over knowledge and position - there were in return an inclination to build a bond based on dialogue as a means of communication and accommodation as a means of solving problems. Obviously, a following surmise could have appeared: this was a marketing measure aiming at constructing a positive image of the whole project and Poland at the same time.

As it has already been mentioned, another element of the persuasive communication was employing specific language, which did not vary a lot from casual speech - it was based on diminutives, emoticons, direct speech. Such a communication type could be analysed in terms of persuasion based on an ingratiation mechanism - its objective could be described as creating a positive attitude of somebody's 
interaction partner in order to fulfil somebody's goals - this kind of behaviour lifts the sender's keeness in interaction partner perception (Witkowski 2004, p. 43-46).

Persuasion had an indirect form - nevertheless, systematic analysis revealed that it could have been treated as a part of the communication strategy of the Polish Presidency Facebook Profile. What is worth emphasizing, is that it was not an overwhelming persuasion but through implementing elements present in day-to-day life of an average individual (such as unofficial expressions or emoticons) it had rather a natural dimension.

\section{CONCLUSIONS}

From the perspective of nearly one year it could be stated that conducting the Polish Presidency Facebook Profile was an enormous challenge - on the one hand, the Team was given a unique opportunity to take adventage of the social media potential, on the other hand however the Team faced an equal threat connected with running a communication process through the specific Internet space which could not have been brought under a traditional control and censorhip.

The Polish Presidency Profile analysis in terms of social communication theory allows us to draw the following conclusions:

1. social media potential usage (in the case of Facebook) - the analysis exposed that the Team responsible for conducting the Polish Presidency Profile was aware of different options available to deploy, especially a possibility of implementing two-way communication with the mass receiver. Indubitably, it was demanding work because of the receivers' diversity and difficulty of defining particular social and demographic profiles of visitors. Motivating Internet users to activity and interacting with them by reacting to their comments inserted below the Team's posts were two important and indispensable factors which contributed to maintain the two-way communication. Furthermore, throughout 6 months of conducting the Polish Presidency Facebook Profile the two-way communication model was consequently maintained, which arguably reinforced the effect of building the Polish Presidency brand.

2. Polish language usage - considering the Polish Presidency as an unique opportunity to promote the positive image of Poland and Poles abroad, conducting the Facebook Profile only in Polish language could be regarded as thought-provoking. It seems probable that it could be regarded as a factor which largely limited the effect of building the positive Poland image through the Polish Presidency Profile containing such a great amount of interesting information which could have enriched foreign receivers' knowledge about Poland and Poles if it had been written in English

3. Transformation of traditional diplomacy - Indubitably, the communication model implemented on the Polish Presidency Facebook Profile (each of the Presidencies could be regarded as a part of diplomacy) has contributed to continuing transformation of the traditional diplomacy. Rather informal language, employing colloquial words and most of all participating and initiating bilateral interactions and maintaining two-way communication have ensured 
that activities once reserved for a narrow group of diplomats become public. Undermentioned aspects of communication could be considered as different tools deployed in public diplomacy and therefore, in my opinion, the Polish Presidency Facebook Profile could have been regarded as a modern measure of conducting Polish public diplomacy

4. Creating a new form of communication - although the communication on the Polish Presidency Facebook Profile should have been classified as mass communication, it had been transformed into a specific form that should be regarded in terms of conjunction of the media interpersonal and direct interpersonal communication - the media direct interpersonal communication appeared as a new type of communication. It could be characterised in particular by changing the indirect form of the traditional media communication by employing photographs or avatars showing personality, attitudes and even values

5. A new dimension of education - the usage of social media in the Polish Presidency campaign could be regarded as a mark of a new form of education - in this case we could talk about a new dimension of image campaign education. In other words, traditional social campaigns tended to deploy old media means (such as television, the press etc.) in order to build the awareness among people. Contemporary campaigns on the contrary are discovering the potential of modern means of communication which allow us to accommodate the message to different group of receivers.

\section{BIBLIOGRAPHY}

Dobek-Ostrowska B. (2004a), Media masowe i aktorzy polityczni w świetle studiów nad komunikowaniem politycznym, Wydawnictwo Uniwersytetu Wrocławskiego, Wrocław.

Dobek-Ostrowska B. (2004b), Podstawy komunikowania społecznego, ASTRUM, Wrocław.

Fiske J. (1999), Wprowadzenie do badań nad komunikowaniem, ASTRUM, trans. A. Gierczak, Wrocław. Głodowski W. (1994), Komunikowanie interpersonalne, Biuro Prasy i Informacji MON, Warszawa.

Knapp M.L., Hall J.A. (1997), Komunikacja niewerbalna w interakcjach międzyludzkich, ASTRUM, trans. A. i L. Śliwa, Wrocław.

Matsumoto D., Juang L (2007), Psychologia międzykulturowa, GWP, trans. A. Nowak, Gdańsk.

Witkowski T. (2004), Psychomanipulacje: jak je rozpoznawać i jak sobie z nimi radzić, Biblioteka Moderatora, Taszów.

\section{NETOGRAPHY}

http://pl2011.eu/program_and_priorities, retrieved: 15.01.2012.

http:/ / www.facebook.com/\#!/PolskaPrezydencja2011?sk=wall, retrieved: 13.01.2012-25.01.2012. 